\title{
Un mundo de víctimas. Gabriel Gatti (ed.) Barcelona: Anthropos, 2017
}

\author{
Carlota Carretero García \\ Universidad Complutense de Madrid \\ carlotacarreterogarcia@gmail.com
}

Desde comienzos del siglo xxI, se ha producido un boom, una explosión en toda regla en lo que respecta al número de ciudadanos y ciudadanas que se piensan y presentan a sí mismos como víctimas. Esta circunstancia ha venido intrínsecamente ligada al correspondiente aumento de la tipología de la víctima, lo que hace de esta categoría un terreno donde englobar desde aquellos agentes tradicionalmente asociados a ella —las víctimas de raíz política - hasta otros asociados con hechos de carácter "ordinario" — como serían las de siniestralidad vial. Lo que anteriormente se entendía como persona vulnerable, hoy se entiende como víctima. De esta manera, la dicotomía víctima-ciudadano se difumina y da paso a una suerte de hibridación entre dos conceptos antaño antagónicos.

Este acontecimiento, sus desencadenantes y la articulación de los mundos de víctimas que acompañan inevitablemente a estas se aborda a lo largo de Un mundo de víctimas, donde se pone el foco particularmente en el caso de España. Este análisis se presenta por medio de una estructura idónea para el tratamiento de algo tan complejo como es explicar la democratización de la categoría "víctima" que se ha producido en las últimas décadas. Dicha estructura está conformada por diferentes bloques, cada uno destinado a un objetivo. Mientras que el primero sirve para sentar las bases de la aproximación teórica, el segundo supone la entrada al campo y la introducción de la tipología de la víctima, resaltando, entre otras cosas, el lugar que ocupa cada tipo respecto a la víctima por antonomasia en la sociedad española, que no es otra que las víctimas de ETA, y las diferencias y particularidades en lo que respecta a su construcción, siendo un ejemplo el de las víctimas de violencia de género, las cuales son entendidas como "víc- timas habladas por otros". Después de presentarnos la tipología de la víctima, en el tercer bloque, se abordan aspectos comunes entre los diversos mundos de las víctimas, tales como la existencia de un cuerpo de especialistas cuyo cometido es el de atender y construir a las víctimas, su entrada al terreno judicial, con las potenciales tensiones de su identidad que eso puede conllevar, el desarrollo de leyes específicas para víctimas o cuestiones como el cuidado, la dignidad o el sufrimiento. Finalmente, parte del último bloque gira en torno a la hipótesis de que se da una "barroquización" en lo que respecta a la manera en la que se nos presenta a las víctimas. Esta cuestión se complementa con el tratamiento del registro del lenguaje de las víctimas y una aproximación al momento en el que se articuló la narrativa de consenso de la Transición respecto a las víctimas de ETA.

Además, este texto trata el fenómeno de las víctimas desde un enfoque multidisciplinar que, por su naturaleza, no atiende únicamente a la dimensión antropológica y/o sociológica del problema, sino que se atreve a zambullirse en el análisis de la configuración de las víctimas de la mano de otras ciencias, como la filología, la historia, la ciencia política o la psicología social, algo que ha ayudado a evidenciar la heterogeneidad de las víctimas, tanto en sus manifestaciones como en sus características y en el reconocimiento que se les otorga. El hecho de optar por un análisis multidisciplinar y multidimensional ha posibilitado una aproximación donde la reconstrucción de la evolución histórica de la categoría "víctima" gana un gran peso a la hora de presentar a las mismas, lo que ha permitido desarrollar un análisis de la coyuntura actual en permanente comparación con el tratamiento que tradicionalmente se les ha dado a las víctimas. 
De esta manera, se logra transmitir a las lectoras y lectores las transformaciones y reformulaciones que han operado a través del tiempo. Esta aproximación tan rigurosa y certera del universo de las víctimas también pone de manifiesto el papel del entramado institucional y el aparato asistencial en la construcción y las reformulaciones a las que se está viendo sometida la categoría "víctima". De este modo, se nos abre la puerta a una comprensión profunda de este suceso, con todos sus matices, especificidades y zonas grises, pero también nos hace conscientes de todo el trabajo que queda por hacer en términos de justicia y reconocimiento de las víctimas. Otro acierto en lo que a estructura y contenido se refiere es que, a lo largo de este libro, no sólo se incluyen las aportaciones multidisciplinares de los y las integrantes del original grupo de investigación, sino que se les da voz a otras reflexiones externas, de manera que se configura una perspectiva interseccional del relato analítico de la víctima.

Respecto al contenido, como ya se ha adelantado, a lo largo de Un mundo de víctimas se desgrana como, durante las últimas décadas, ha comenzado a producirse la democratización de la categoría "víctima", así como la resignificación del concepto. Se ha pasado de un enfoque en el que primaba la construcción de víctima como ese mártir necesario para la instauración de la normalidad — condición restringida a la que no podía acceder cualquiera - a, en la actualidad, una proliferación del ciudadano-víctima, cuya cualidad distintiva, tal y como indica su nombre, es precisamente su accesibilidad, ya que cualquier ciudadano 0 ciudadana puede presentarse y pensarse como víctima. En otras palabras, de acuerdo con el texto, hemos pasado de que la víctima sea vista a ojos de la sociedad como un héroe 0 un mártir —o sea, alguien fuera de lo común-a que, en la actualidad, esta categoría haya ganado centralidad y crecido en número y variantes. La víctima se conforma, pues, como un nuevo "tipo subjetivo", en palabras de Gatti.

Dicha evolución de la categoría "víctima" se produce de la mano de multitud de dispositivos que han provocado que, en la actualidad, sea una categoría plural, tanto en las características de su tipología como en el reconocimiento social e institucional que ostentan. Algunos de los casos más relevantes en los que se centra este libro, como ya se ha adelantado en párrafos anteriores, son las víctimas de raíz política, las víctimas de la violencia de género, las de los accidentes de tráfico y los bebés robados. Cada uno de estos tipos de víctimas posee particularidades respecto a su construcción subjetiva, su autopercepción, vivencias y relación con el significado y las implicaciones de lo que supone "ser víctima". No obstante, si bien el universo de las víctimas es variado, hay algo que, inequívocamente, las une a todas a pesar de las diferencias, y ese algo es el sufrimiento que las ha definido como tales, conformándolas como una "comunidad del dolor". Todo esto se explora a lo largo de esta publicación, donde — con atención, respeto y precisión- se aborda, con todos los matices y reservas, el análisis de esta categoría multipolar, siempre desde la complejidad y evitando caer en una condescendencia político-moral.

Sin embargo, a pesar de la reciente apertura de dicha categoría, no todas las víctimas cuentan con el mismo nivel de visibilidad y reconocimiento social e institucional. Un caso paradigmático es el de las víctimas del franquismo, las cuales, históricamente, no han recibido ni reconocimiento ni reparación, siendo desterradas de la memoria y condenadas al ostracismo, a diferencia de como ocurre con otras víctimas de raíz política como las víctimas de ETA. Tal y como se explica en esta publicación, ha sido alrededor de estas últimas en torno a las cuales se ha articulado la narrativa de consenso formulada y puesta en circulación durante la afamada Transición, con el objetivo de establecer marcos de sentido compartidos. Este suceso se visibiliza en este libro, de manera que, no sólo se procede a realizar un análisis de una problemática específica, sino que, paralelamente, se hace un ejercicio de justicia y reconocimiento respecto a unas víctimas que, hasta muy recientemente, habían sido dejadas de lado.

Por lo tanto, Un mundo de víctimas es una lectura altamente recomendable e imprescindible para cualquier público, tanto para aquellas personas que deseen desarrollar una política pública centrada en este tema, hacer una aproximación 
teórica 0 , simplemente, tener una comprensión y una mirada más certeras de los movedizos tiempos en los que vivimos. Además, la originalidad de la perspectiva por la que se ha optado en la elaboración de este trabajo hace de este texto una lectura que puede servir no sólo para hacer una interesante reflexión sociológica sobre una categoría extremadamente actual, sino también como inspiración a la hora de articular una estructura que soporte la construcción de futuras investigaciones. 
